Research Article

\title{
Anxiolytic potential of astaxanthin on experimental animal model
}

\author{
Rekha Mehani $^{1 *}$, Vijay Kumar $\operatorname{Yadav}^{2}$, Rajnish Sankadia ${ }^{3}$
}

${ }^{1}$ RKDF Medical College and Research Centre, Bhopal, India,

${ }^{2}$ PCMS RC, Bhanpur, Bhopal, India, ${ }^{3}$ Chirayu Medical College Bhopal, India

Received: 03 November 2015

Accepted: 06 January 2016

*Correspondence to:

Dr. Rekha Mehani,

Email: drrekhasanjay@gmail.com

Copyright: (c) the author(s), publisher and licensee Medip Academy. This is an open-access article distributed under the terms of the Creative Commons Attribution Non-Commercial License, which permits unrestricted noncommercial use, distribution, and reproduction in any medium, provided the original work is properly cited.

\begin{abstract}
Background: Astaxanthin is a naturally occurring carotenoid found in nature primarily in marine organisms. Carotenoids are well known for their therapeutic benefits in the aging process and various diseases, because of their antioxidant properties. Additionally, astaxanthin has well-documented anti-inflammatory and immune-stimulating effects. It is a known fact that oxidative stress is associated with depression, anxiety, and related psychiatric disorders. Astaxanthin may also reduce oxidative stress in the nervous system, reducing the risk of neurodegenerative diseases. Although astaxanthin has the ability to cross the blood-brain barrier and has a beneficial effect on the CNS, the effects of astaxanthin on anxiety and depression have not been reported.

Methods: In this study, to investigate the effects of astaxanthin on anxiety, we performed some behavioural tests including elevated plus maze test, hole-board test, light/dark exploration test.

Results: In elevated plus maze test the time spent in the closed arm by astaxanthin treated rats was significantly $(\mathrm{P}<0.05)$ decreased as compared to control. The number of readings in both the arms was significantly ( $\mathrm{P}$ $<0.05$ ) increased in astaxanthin treated rats as compared to control. In hole board apparatus, it showed anxiolytic response by significantly reduced the number of head poking. Increased number of entries in the bright side and decrease of time spent by the animal in dark side were observed in the light/dark exploration test.

Conclusions: The present study indicates that Astaxanthin produces anxiolytic response at the dose of $3 \mathrm{mg} / \mathrm{kg}$ on experimental animal model.
\end{abstract}

Keywords: Astaxanthin, Diazepam, Anxiety

\section{INTRODUCTION}

Astaxanthin is a naturally occurring carotenoid found in nature primarily in marine organisms Carotenoids are well known for their therapeutic benefits in the aging process and various diseases, because of their antioxidant properties. $^{1}$ Additionally, astaxanthin has welldocumented anti-inflammatory and immune-stimulating effects.

It has the ability to be located either inside the phospholipid membrane or at the membrane surface and to cross the blood-brain barrier in rodents. ${ }^{2,3}$ In the central nervous system (CNS), astaxanthin has been reported to protect against ischemia/reperfusion-induced neurodegeneration in rats, and affects cognitive functioning in humans. ${ }^{4,5}$ Strong antioxidant property of astaxanthin is responsible for the hosting of beneficial effects in human including decreasing oxidative DNA damage, decreasing biomarkers of inflammation, positive effects on lipid profile, boosting of immunity and improvement in cognition. ${ }^{5-8}$ Apart from this, astaxanthin also showed improved memory performance in mice and protection of nerve cells against oxidative stress in various in-vitro studies. ${ }^{9,10}$ Certain CNS disorders such as anxiety and depression in humans have been shown to have multifactorial causes and one of the cause could be the oxidative stress. ${ }^{11}$ As we all know that oxidative stress is associated with depression, anxiety, and related psychiatric disorders. Astaxanthin may also reduce oxidative stress in the nervous system, reducing the risk of neurodegenerative diseases. Although astaxanthin has the ability to cross the blood-brain barrier and has a beneficial effect on the CNS, the effects of astaxanthin on anxiety have not been reported. In this study, we investigated the effects of astaxanthin as an adjuvant in addition to standard drug on anxiety in rat models. 


\section{METHODS}

\section{Animals}

Four-week-old male rats, weighing 150-250 g, were used in this study. The animals were obtained from animal house of Peoples College of Medical Science/Research Centre Bhopal. All procedures relating to animal care and treatment conformed to the animal care guidelines of the Animal Experiment Committee.

All efforts were made to minimize both suffering and the number of animals used. The animals were housed at 24 $\pm 2{ }^{\circ} \mathrm{C}$ under a $12 \mathrm{~h}$ light-dark cycle (lights on from 8:00 to 20:00) and had ad libitum access to food and water. Behavioral experiments were performed between 10:00 and 16:00.

\section{Administration of astaxanthin}

Astaxanthin obtained from MyNutraMart, Bangalore and mixed with wheat flour. In evaluation of antianxiety-like behaviours, astaxanthin was orally administrated at the dose of $3 \mathrm{mg} / \mathrm{kg} /$ day for 15 days. $1 \mathrm{~h}$ after the last administration, the animals was subjected to the experiment.

Animals were divided into 3 groups of 6 animals each. Three groups made for each test were control group, standard drug group and standard drug with astaxanthin group. Tests performed for anxiety studies were elevated plus maze, Hole board test and light/dark exploration test.

\section{Elevated plus maze}

The elevates plus maze consisted of two opposite arms $(50 \mathrm{~cm} \times 10 \mathrm{~cm})$ crossed with two opposite enclosed arms of the same dimension with $40 \mathrm{~cm}$ high walls. The arms were connected with a central square $(10 \mathrm{~cm} \times 10$ $\mathrm{cm})$ to give the apparatus a plus sign appearance. ${ }^{12}$ The maze was kept elevated $50 \mathrm{~cm}$ above the floor in a dimlylit room. The rats were individually placed on the central square of the plus maze facing on enclosed arm. The time spent and numbers of entries made by the rats, during the next $5 \mathrm{~min}$, on open and enclosed arms were recorded. An arm entry was defined when all the four limbs were on the arm.

\section{Hole board test}

The hole board apparatus consisted of a wooden box (40 $\times 40 \times 25 \mathrm{~cm}^{3}$ ) with 16 holes (each of diameter $3 \mathrm{~cm}$ ) evenly distributed on the base of box. ${ }^{13}$ The apparatus was elevated to the height of $25 \mathrm{~cm}$. Rats were treated with Astaxanthin $3 \mathrm{mg} / \mathrm{kg}$ before they were placed in the apparatus. The head-dipping duration and head-dipping counts during a 5 min period were recorded. ${ }^{14}$

\section{Light/dark exploration test}

Light-dark box $(40 \mathrm{~cm} \times 20 \mathrm{~cm} \times 20 \mathrm{~cm})$ consists of two parts, the light-compartment and the dark compartment with a volume ratio of $3: 1$. The box consists of a hole $(5 \mathrm{~cm} \times 5 \mathrm{~cm})$ in the bottom of the clapboard between the two compartments. A $60-\mathrm{W}$ incandescent bulb above provided illumination for the open light compartment and $0 \mathrm{~lx}$ for the enclosed dark compartment. During the test the rats were put into the center of the light compartment with their back to dark compartment and then transition behavior over 5 min was observed. ${ }^{15}$

1. Latency to the first crossing to the dark compartment.

2. Number of crossings between the light and dark area.

3. Total time spent in the illuminated part of the box.

4. Rearing.

Every time before placing each animal, the maze was cleaned with $5 \%$ alcohol to eliminate the possible bias due the odour left by the previous animal.

\section{Statistical analysis}

Data are presented as the means \pm S.E.M. Statistical comparisons were made by a Student's t-test or a oneway ANOVA, with $\mathrm{P}<0.05$ being considered to indicate a statistical significance.

\section{RESULTS}

\section{Elevated plus maze}

In the elevated plus maze, avoidance of the open arms, an increase in the time spent in the closed arms and a decrease in rearing indicates anxiety. ${ }^{16,17}$ In the elevated plus maze model, the time spent by astaxanthin treated rats in the open arm was significantly $(\mathrm{p}<0.05)$ increased as compared to control. The time spent in the closed arm by astaxanthin treated rats was significantly $(\mathrm{p}<0.05)$ decreased as compared to control (Figure 1). The number of readings in both the arms was significantly $(p<0.05)$ increased in astaxanthin treated rats as compared to control.

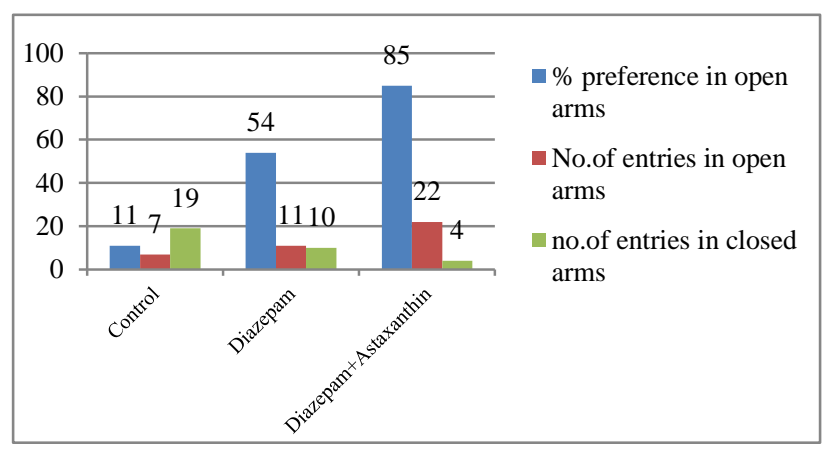

Figure 1: Elevated plus maze. 


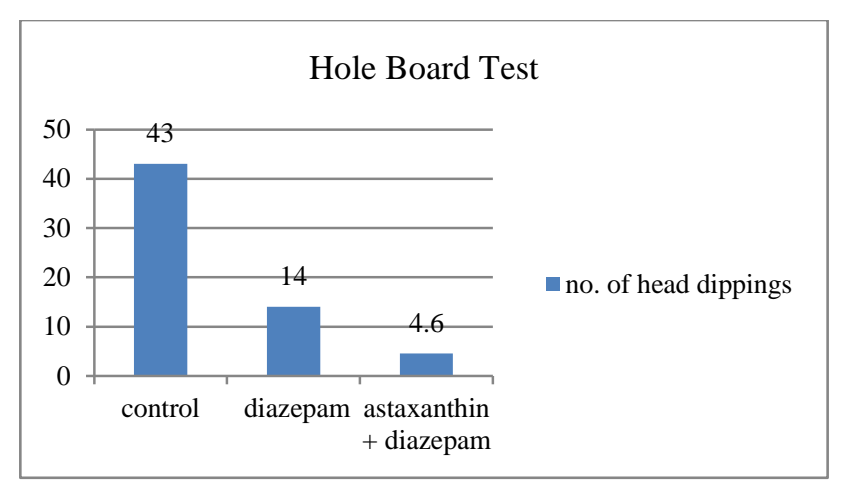

Figure 2: Hole board test.

\section{Hole-board test}

Head dipping behaviour of the animals in the Hole Board test is considered to be an indicator of anxiety. ${ }^{18,19}$ Decreased frequency and duration of the head dipping is an indicator of anxiolytic state. As a positive standard, Diazepam significantly decreases both the frequency and duration of head dipping ( $p<0.01$ ) but in comparison with astaxanthin ( $3 \mathrm{mg} / \mathrm{kg} /$ day) administered along with the standard drug, it produced an even more significant antianxiety effect $(p<0.01)$ and Figure 2 shows that the addition of astaxanthin greatly enhances the activity of diazepam to produce the antianxiety effect.

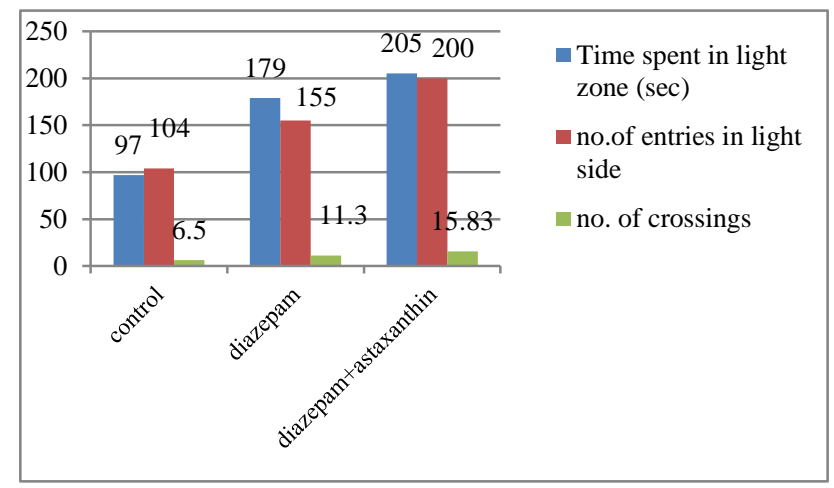

Figure 3: Light/dark exploration test.

\section{Light/dark exploration test}

On the 14th day of the treatment there was significant increase in time spent in light zone in mice treated with astaxanthin $3 \mathrm{mg} / \mathrm{kg} \quad(179.0 \pm 5.89) \quad(\mathrm{p}<0.001)$, when compared with control (97.32 \pm 3.71$)$. There was significant increase in number of crossings in rats treated with astaxanthin $(15.83 \pm 1.01) \quad(\mathrm{p}<0.001)$, when compared with control $(6.5 \pm 0.76)$. The number of readings in both the zones was significantly $(\mathrm{p}<0.05)$ increased in astaxanthin treated rats as compared to control elevated plus maze.

\section{DISCUSSION}

The effects of astaxanthin on CNS as discussed earlier could be because of its strong antioxidant nature and its ability to scavenge free radicals which might offer significant neuroprotection. ${ }^{19-21}$ There are several studies linking oxidative stress as one of the causes of anxiety and depression in rat model of psychiatric disorder and reversal of oxidative stress induced anxiety by inhibition of phosphodiesterase. ${ }^{11}$ In our study we tried to seek the information on any beneficial role of astaxanthin as an adjuvant to the standard drug prescribed for the treatment of anxiety. In the experiments on anxiety, astaxanthin has shown remarkable adjunctive value in terms of increase in effectiveness of the standard treatment.

\section{CONCLUSION}

The present study indicates that astaxanthin produces anxiolytic response at the dose of $3 \mathrm{mg} / \mathrm{kg}$ on experimental animal model.

Funding: No funding sources

Conflict of interest: None declared

Ethical approval: The study was approved by the Institutional Animal Ethics Committee

\section{REFERENCES}

1. Fassett RG, Coombes JS. Astaxanthin: a potential therapeutic agent in cardiovascular disease. Mar Drugs. 2011;9:447-65.

2. Kistler A, Liechti H, Pichard L, Wolz E, Oesterhelt G, Hayes A, et al. Metabolism and CYP-inducer properties of astaxanthin in man and primary human hepatocytes. Arch Toxicol. 2002;75:665-75.

3. Goto S, Kogure K, Abe K, Kimata Y, Kitahama $\mathrm{K}$, Yamashita E, et al. Efficient radical trapping at the surface and inside the phospholipid membrane is responsible for highly potent antiperoxidative activity of the carotenoid astaxanthin. Biochim Biophys Acta. 2001;1512:251-8.

4. Park JS, Chyun JH, Kim YK, Line LL, Chew BP. Astaxanthin decreased oxidative stress and inflammation and enhanced immune response in humans. NutrMetab. 2010;7:18.

5. Genest J. C-reactive protein: risk factor, biomarker and/or therapeutic target? Can J Cardiol. 2010;26:41A-4A.

6. Yoshida $\mathrm{H}$, Yanai $\mathrm{H}$, Ito $\mathrm{K}$, Tomono $\mathrm{Y}$, Koikeda $\mathrm{T}$, Tsukahara $\mathrm{H}$, et al. Administration of natural astaxanthin increases serum HDL-cholesterol and adiponectin in subjects with mild hyperlipidemia. Atherosclerosis, 2010;209:520-3.

7. Satoh A, Tsuji S, Okada Y, Murakami N, Urami $\mathrm{M}$, Nakagawa $\mathrm{K}$, et al. Preliminary clinical evaluation of toxicity and efficacy of a new astaxanthin-rich Haematococcus pluvialis extract. J Clin Biochem Nutr. 2009;44:280-4.

8. Zhang X, Pan L, Wei X, Gao H, Liu J. Impact of astaxanthin-enriched algal powder of Haematococcuspluvialison memory improvement in BALB/c mice. Environ Geochem Health. 2007;29:483-9. 
9. Hussein G, Nakamura M, Zhao Q, Iguchi T, Goto H, Sankawa U. Antihypertensive and neuroprotective effects of astaxanthin in experimental animals. Biol. Pharm. Bull. 2005;28:47-52.

10. Masood A, Nadeem A, Mustafa SJ, O’Donnell JM. Reversal of oxidative stress-induced anxiety by inhibition of phosphodiesterase- 2 in mice. J Pharmacol Exp Ther. 2008;326:369-79.

11. Nishioka Y, Oyagi A, Tsuruma K, Shimazawa $\mathrm{M}$, Ishibashi T, Hara $\mathrm{H}$. The antianxiety like effect of astaxanthin extracted from Paracoccus Carotinifaciens. International Union of Biochemistry and Molecular Biology. 2011;37(1):25-30 .

12. Tsuji M, Takeda H, Matsumiya T. Method for evaluation of emotionality in preclinical studies: usefulness of the hole-board test. Nippon Yakurigaku Zasshi. 2005;126:88-93.

13. Porsolt RD, Le Pichon M, Jalfre M. Depression: a new animal model sensitive to antidepressant treatments.Nature. 1977;266:730-2.

14. Barua CC, Roy JD, Buragohain B, Barua AG, Borah P, Lahkar M. Anxiolytic effect of hydroethanolic extract of Drymarai cordata L wild. Indian J. Exp. Biol. 2009;47:969-73.

15. Suzuki T, Amata M, Sakaue G, Nishimura S, Inoue T, Shibata M. Experimental Neuropathy in mice is associated with delayed behavioral changes related to anxiety and depression. Int Anesthesia Res Soc. 2007;104:6.
16. Pellow S, Chopin P, File SE, Briley M. Validation of open:closed arm entries in an elevated plus-maze as a measure of anxiety in the rat. $\mathbf{J}$ Neuroscience Methods. 1985;14(3):149-67.

17. Fernández Espejo E. Structure of the mouse behaviour on the elevated plus-maze test of anxiety.Behav Brain Res. 1997;86(1):105-12.

18. Zhang X, Pan L, Wei X, Gao H, Liu J. Impact of astaxanthin-enriched algal powder of Haematococcus pluvialis on memory improvement in BALB/c mice. Environ Geochem Health. 2007;29:483-9.

19. Lu YP, Liu SY, Sun H, Wu XM, Li JJ, Zhu L. Neuroprotective effect of astaxanthin on $\mathrm{H}_{2} \mathrm{O}_{2}$ induced neurotoxicity in vitro and on focal cerebral ischemia in vivo. Brain Res. 2010;1360:40-8.

20. Bouayed J, Rammal H, Younos C, Soulimani R. Positive correlation between peripheral blood granulocyte oxidative status and level of anxiety in mice. Eur J Pharmacol. 2007;564:146-9.

21. Burt DR. Reducing GABA receptors. Life Sci. 2003;73:1741-58.

Cite this article as: Mehani R, Yadav VK, Sankadia R. Anxiolytic potential of astaxanthin on experimental animal model. Int J Basic Clin Pharmacol 2016;5:1314. 